\title{
ERRATUM
}

Hitoshi Iwahashi · Hisayo Shimizu

Mine Odani · Yasuhiko Komatsu

\section{Piezophysiology of genome wide gene expression levels in the yeast Saccharomyces cerevisiae}

Published online: 13 September 2003

(C) Springer-Verlag 2003

\section{Extremophiles (2003) 7:291-298}

The legend for figure 4 in the above-mentioned article was inadvertently omitted during file conversion. The legend is as follows:

Fig. 4. Functional characterization of induced genes (40MPa) according to the MIPS categories. The genes selected to be induced were grouped according to the functional categories of MIPS using GeneSpring. The percentage was calculated as follows: (number of genes induced by pressure) / (number of genes in the categories) $\times 100$

The online version of the original article can be found at http:// dx.doi.org/10.1007/s00792-003-0322-y

H. Iwahashi $(\square)$

Human Stress Signal Research Center,

National Institute of Advanced Industrial Science and Technology, Central-6, Higashi 1-1, Tsukuba 305-8566,

Ibaraki, Japan

E-mail: hitoshi.iwahashi@aist.go.jp

Tel.: + 81-29-8616066

Fax: + 81-29-8616066

H. Iwahashi · H. Shimizu · M. Odani · Y. Komatsu

International Patent Organism Depositary,

National Institute of Advanced Industrial Science and Technology, Central-6, Higashi 1-1, Tsukuba 305-8566, Ibaraki, Japan 